\title{
Feedstock Pathways for Bio-Oil and Syngas Conversion Pathways
}

David Muth Jacob Jacobson Kara Cafferty Robert Jeffers

March 2013

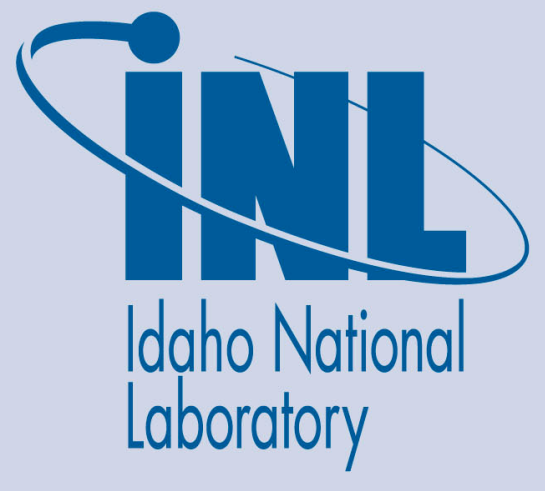

The INL is a U.S. Department of Energy National Laboratory operated by Battelle Energy Alliance 
INL/EXT-13-29487

TM2013-004-0

\title{
Feedstock Pathways for Bio-Oil and Syngas Conversion Pathways
}

\author{
David Muth \\ Jacob Jacobson \\ Kara Cafferty \\ Robert Jeffers
}

March 2013

\begin{abstract}
Idaho National Laboratory
Idaho Falls, Idaho 83415
\end{abstract}

http://www.inl.gov

Prepared for the

U.S. Department of Energy

Assistant Secretary for Energy Efficiency and Renewable Energy

Under DOE Idaho Operations Office

Contract DE-AC07-05ID14517 
To: $\quad$ Bioenergy Technology Office, US Department of Energy

Title: $\quad$ Feedstock Pathways for Bio-oil and Syngas Conversion Pathways

Author: $\quad$ Dave Muth, Jake Jacobson, Kara Cafferty, Robert Jeffers

Platform: $\quad$ Feedstock Analysis

Date: $\quad$ March 2013

Number: $\quad$ TM2013-004-0 INL/EXT-13-29487

\section{PURPOSE}

The goal of this technical memorandum is to support the DOE strategic goal of demonstrating \$3/gge drop-in hydrocarbon biofuel production in 2017. A critical component of achieving that goal is developing supply chains that can deliver high quality, low cost biomass to the biofuel conversion reactor throat. This report develops a biomass supply chains that utilize advanced preprocessing strategies to achieve the \$80/DMT reactor throat feedstock cost target while consistently achieving the targeted feedstock specifications for the both the bio-oil and syngas conversion technology pathways. 


\section{BACKGROUND}

In FY12, the conventional biomass supply system design was completed by implementing field and PDUscale data from harvest, collection, storage, preprocessing, handling, and transportation operations into INL's Biomass Logistics Model (BLM) and showing an achieved overall supply system cost of \$35 per dry matter ton (DMT) or less in 2007 dollars for dry corn stover. This previous work was focused on a niche crop in a high yield area. These types of supply systems were proven to be able to achieve the cost targets for small volumes of material moving through the system. However, these conventional supply systems (CSS) by design do not have the ability to actively manage the feedstock characteristics such as moisture and ash content as influenced by the local climate and supply chain management practices. Because of this conversion facilities are required to handle the operational impacts from biomass variability. In response, more robust biofuel conversion technologies are being developed, even though it is unlikely a single best conversion technology will be capable of handling the variability experienced within raw biomass feedstocks. DOE has identified eight biofuel conversion pathways that the Bioenergy Technologies Office (BETO) is currently supporting R\&D toward. This report develops baseline feedstock pathways to support the conversion pathways using cellulosic sugars and bio-oil via fast pyrolysis that can deliver on-spec feedstocks at the conversion reactor throat for less than $\$ 80 /$ dry metric ton (reported in \$2011).

DOE has established a strategic goal of demonstrating $\$ 3 /$ gge drop-in hydrocarbon biofuel production in 2017. A critical component of achieving that goal is developing supply chains that can deliver high quality, low cost biomass to the biofuel conversion reactor throat. Based on current R\&D projections for the conversion technologies a reactor throat feedstock cost of \$80/dry metric ton (reported in \$2011) has been identified as the maximum allowable cost for the feedstock supply chain to achieve the $\$ 3 /$ gge target. There are a range of low cost and niche biomass materials which can be used to achieve the \$80/DMT target. The challenge is that low cost biomass will typically not achieve the specifications required for the conversion processes. This report develops two biomass supply chains that utilize advanced preprocessing strategies to achieve the \$80/DMT reactor throat feedstock cost target while consistently achieving the targeted feedstock specifications. One of the supply chain designs delivers biomass for production of cellulosic sugars and upgrading to drop-in hydrocarbon biofuels. The other supply chain design delivers biomass for fast pyrolysis to bio-oil with upgrading to drop-in hydrocarbon biofuels.

\section{The Feedstock Quality Challenge}

A current feedstock supply chain challenge is to reduce the natural variability of the feedstock quality to reduce the impacts to the conversion efficiencies and thus reduce the overall cost of producing biofuel (Figure 1). Additionally, when examining the various characteristics of biomass and comparing the results against the conversion requirements, there is a very limited amount of biomass that meets the in-feed specifications (Figures 2-4). From the feedstock perspective, the questions that arise are can we select, blend or alter somewhere in the logistic supply chain the feedstock so that more of the material will meet the in-feed requirements. 
Histogram of MESPs for 735 Stover Compositions

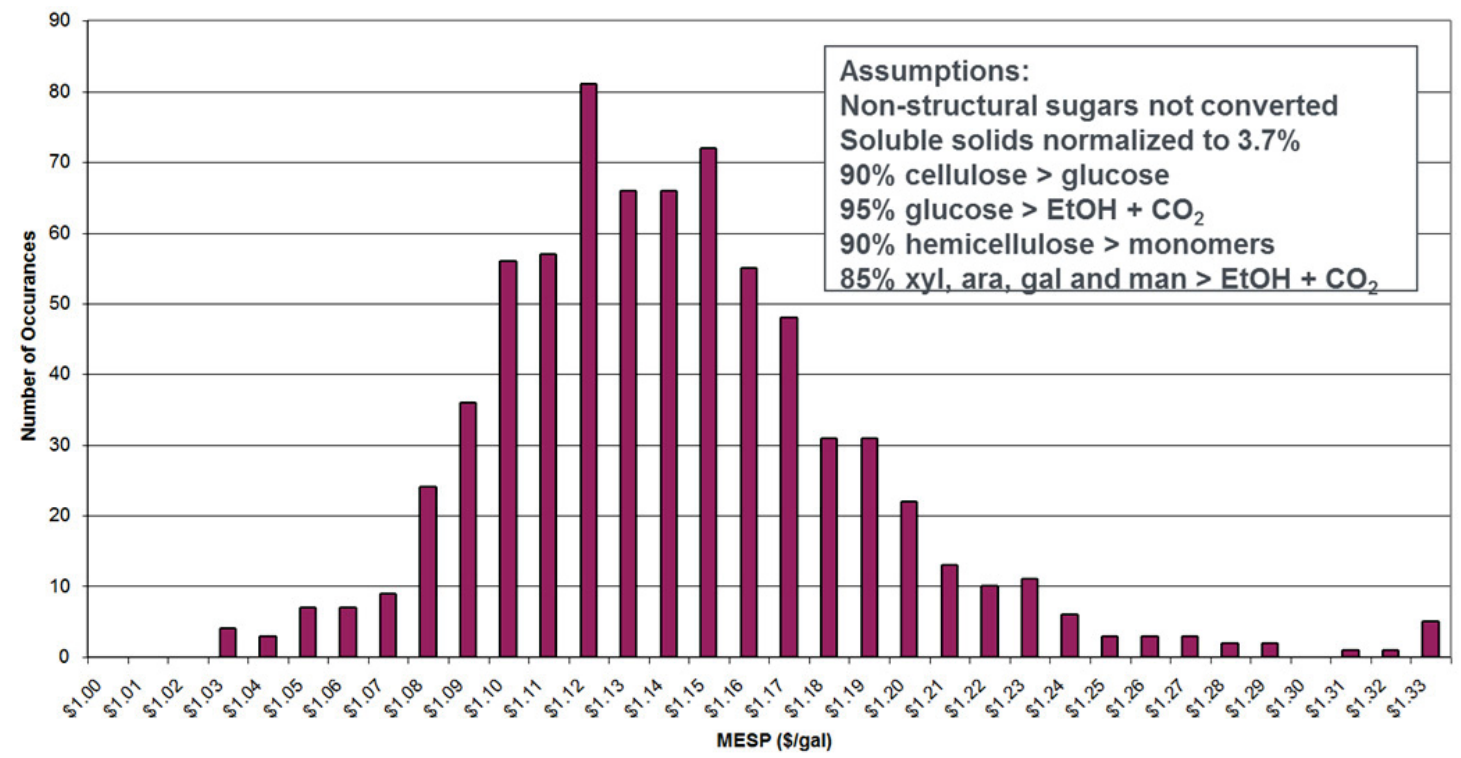

Figure 1: Impacts of variability of sugars to the final MESP price (\$/gal).
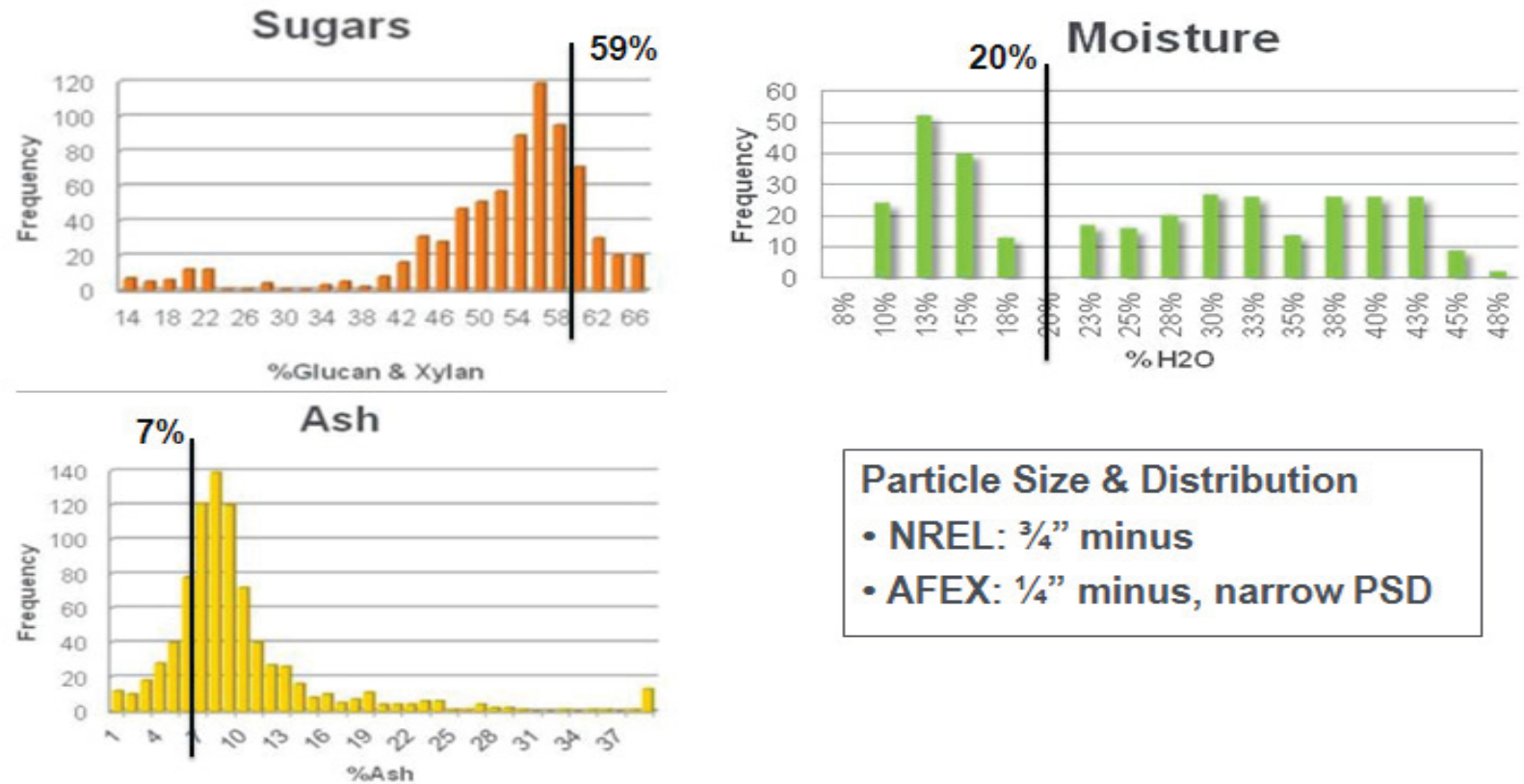

\section{Particle Size \& Distribution \\ - NREL: $3 / 4$ " minus \\ - AFEX: 1/4" minus, narrow PSD}

Figure 2: Quality variability versus the design specifications for a biochemical conversion process. 

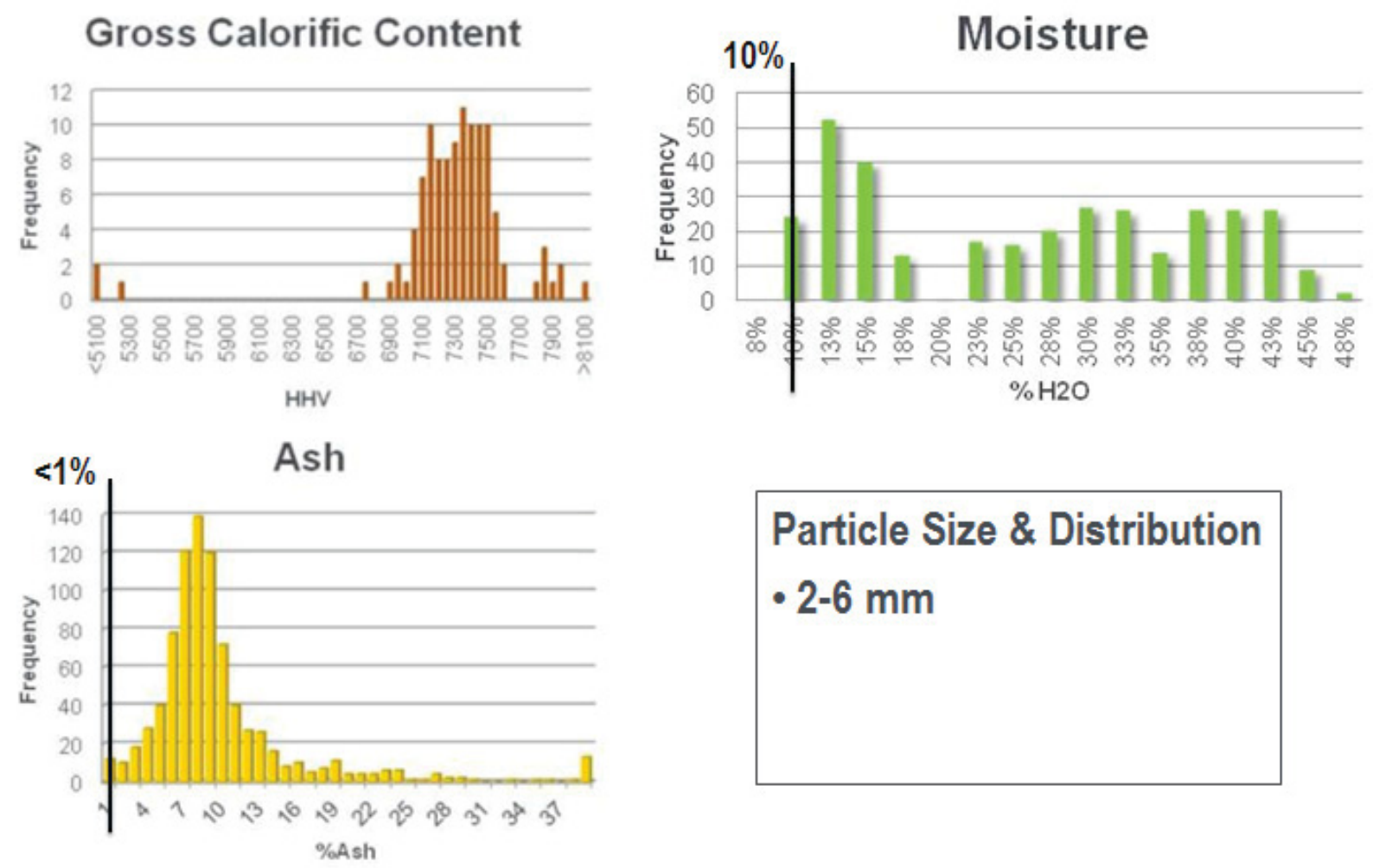

Figure 3: Qualilty variablity versus the in-feed specifications for a thermochemical conversion process.

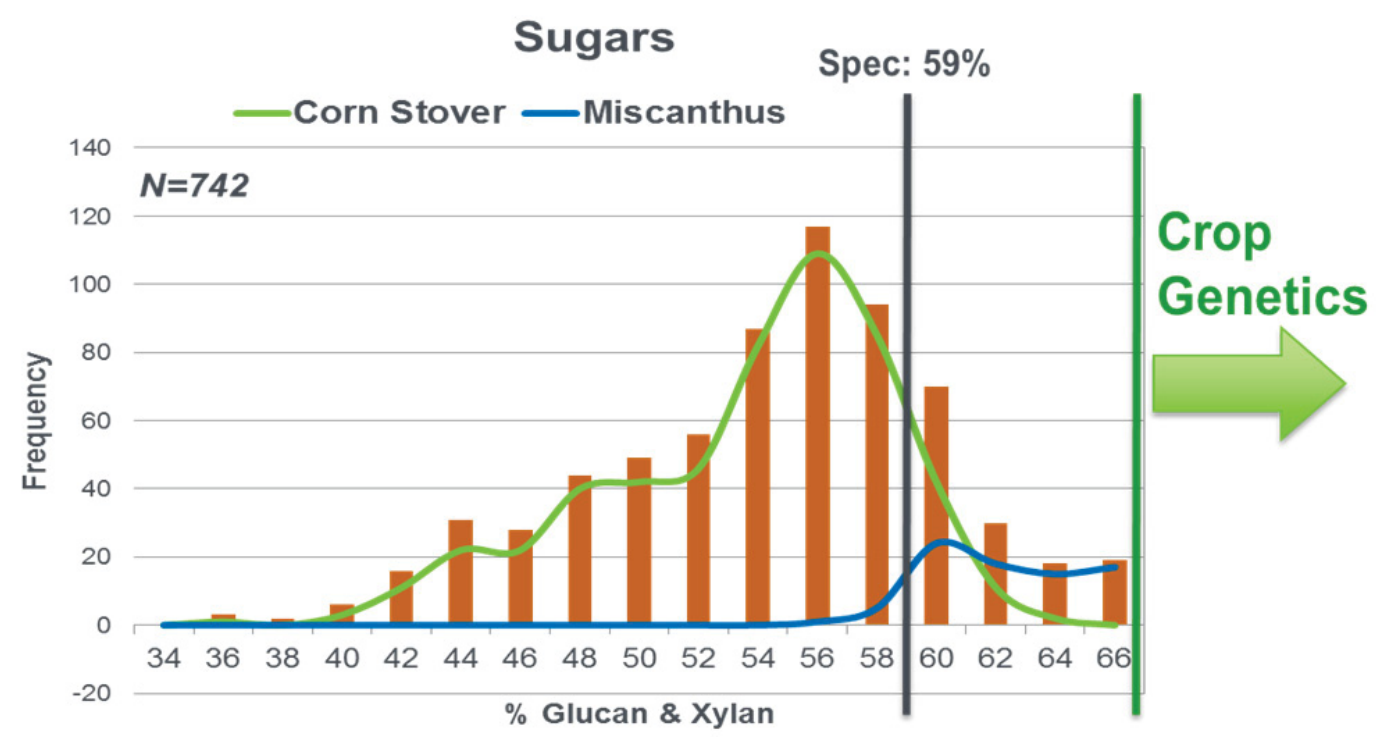

Figure 4: Variability of sugars by crop type compared against the in-feed specification. 
The advanced preprocessing concept is to blend multiple feedstocks to get the blended material to meet the in-feed requirements. This will take high quality, high cost material that meets or exceeds the in-feed requirements and blend it with low quality, low cost material. This process does three things: 1) it reduces the overall cost of the material by blending high cost with low cost to come up with a cost in the middle, 2) it reduces variability of the final blended material since we are blending to a certain criteria, 3 ) it brings more material into the supply system that would not qualify without some type of blending strategy. Figure 5 and 6 outline the concept of blending feedstocks to adjust the blended material to meet the in-feed requirements of the conversion facility.

Formulation

- Aggregation blending of same biomass type to spec

- Blending multiple resource types to spec

- Amendmentblend with source of cheap sugars

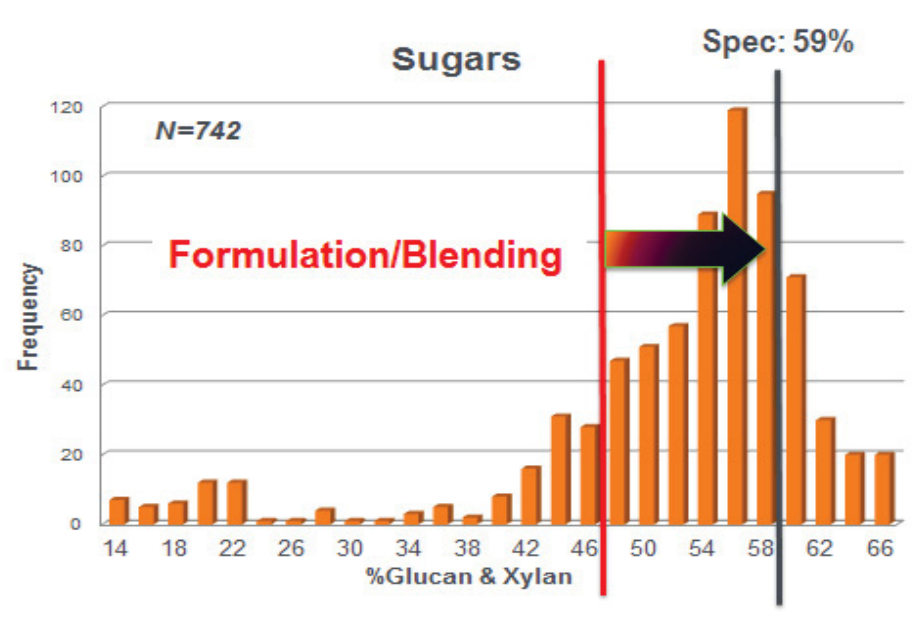

Figure 5: Demonstration of blending multiple feedstocks to achieve the formulation target.

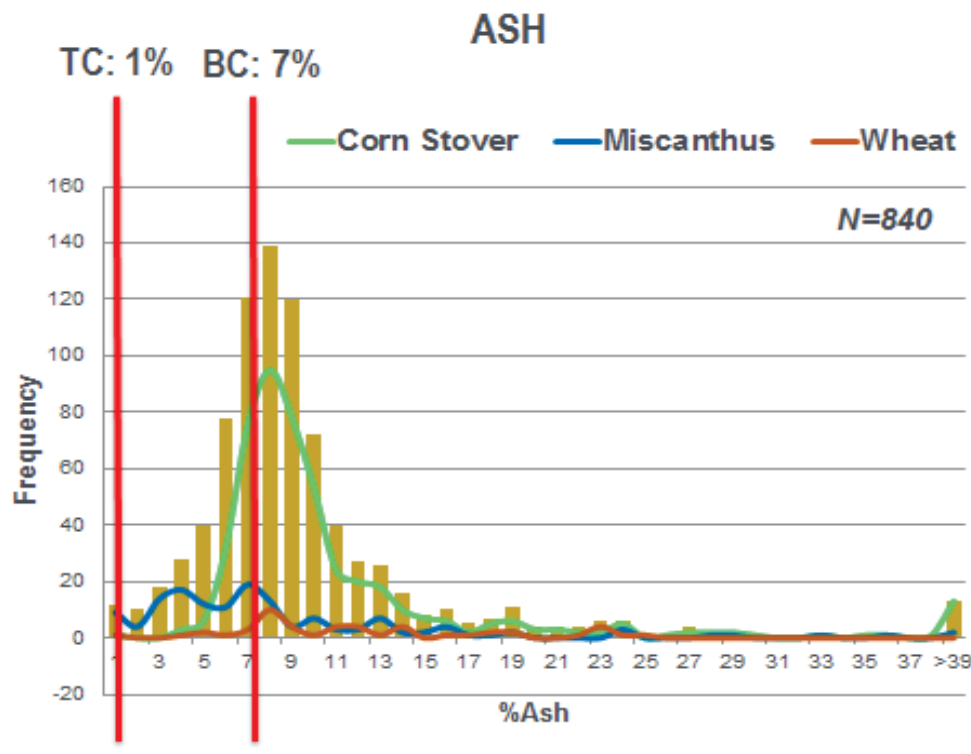

- Selection of optimum feedstock

- Risk: Reliance on specific biomass resources

- Results in boutique feedstocks

Figure 6: Demonstrates the need to blend corn stover with miscanthus in order to meet the infeed requirements of the conversion technology. 
Finally, we are moving towards a more advanced feedstock supply chain that includes advanced preprocessing unit operations to actively manage biomass quality characteristics. We can design process that clean up the biomass and bring it in-line with the in-feed requirements (Figure 7).

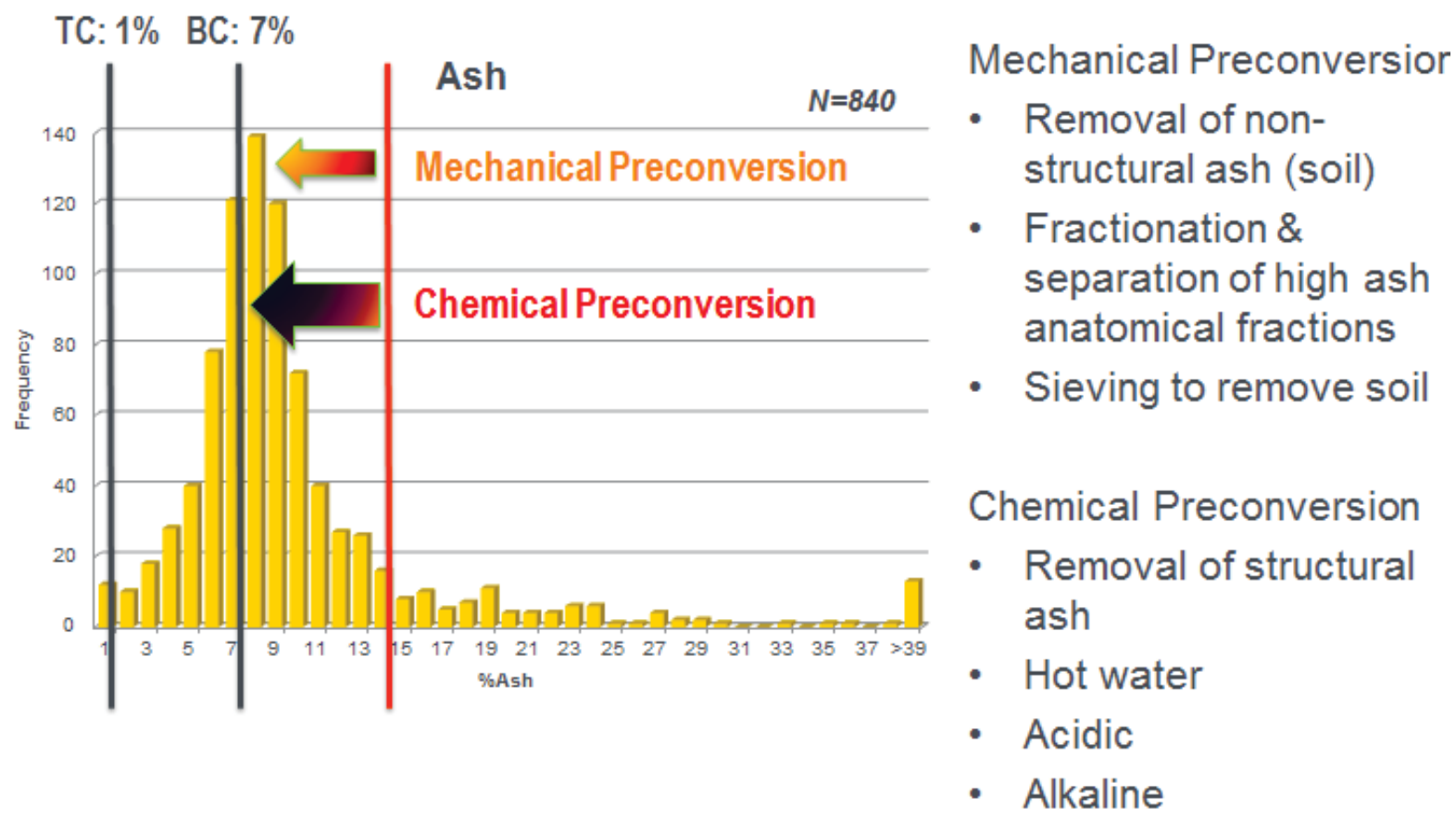

Figure 7: Preconversion then takes us to the final specifiation.

\section{Biomass Supply Chain Design}

The primary advanced preprocessing technology used to achieve the \$80/DMT is feedstock formulation. Formulation allows the use of low cost, but typically low quality, biomass blended with higher cost and quality biomass to achieve conversion quality specifications. Formulation also allows the feedstock supply chain business units to adapt to changing market costs and feedstock quality requirements to continue delivering low cost biomass to the conversion reactor throat. Furthermore, the use of low cost biomass allows the supply chain to implement additional preprocessing technologies that actively control feedstock quality.

The first step in developing these baseline scenarios was investigating the regional biomass production supply curves from the US Billion Ton Update to identify "high impact" scenarios to develop and demonstrate the 2017 feedstock supply chain scenarios at the \$80/DMT target. Two regional scenarios emerged for the baseline system R\&D development and demonstration. The first is a Midwest US scenario delivering a formulated feedstock for cellulosic sugar based conversion pathways. The second is a SE US scenario delivering a formulated feedstock for bio-oil based conversion pathways. It is important to note that the baseline scenarios are regionally focused in order to establish feedstock costs and supply chain technical performance requirements, but the supply chain technologies and designs are broadly applicable across the US. 


\section{Bio-gas and Syngas Conversion Pathway Supply Chains}

The feedstock supply chain designs for thermochemical biofuel conversion systems, specifically focused on fast pyrolysis, are typically focused on delivering clean wood chips to the reactor throat. This presents both cost and feedstock quality challenges in trying to achieve the \$80/DMT target. Using the Least Cost Formulation Spatial Tool a high impact formulation based forest thinning, logging residues, and loblolly pine creates an opportunity to meet the feedstock cost and quality targets for bio-oil and syngas conversion pathways (Figure 8).

Forest thinning and logging residues are low cost resources to procure, but also have unfavorable quality specs, specifically ash content. Because these resources are low cost supply chains that include active ash management preprocessing unit operations can be included. Specifically in this design a hot water extraction unit operation is used to reduce the ash content. The identified formulation uses $40 \%$ forest thinnings, $40 \%$ logging residues, and $20 \%$ purpose grown pine (Table 1 ). The forest thinning and logging residues are reduced to $2.25 \%$ and $2.25 \%$ ash respectively with the hot water extraction unit operation. The purpose grown pine is debarked and chipped at the landing resulting in an ash content of $0.5 \%$. Forest thinnings and logging residues are delivered through supply chains that include the ash reduction unit operation at costs below the \$80/DMT target, but the ash reduction technology has not yet been demonstrated to achieve levels below $2 \%$. The $20 \%$ fraction of clean pine chips does not meet the cost target coming in at nearly \$100/DMT, but provides low ash material to support meeting that conversion spec. The complete formulation meets both the cost and feedstock quality targets.

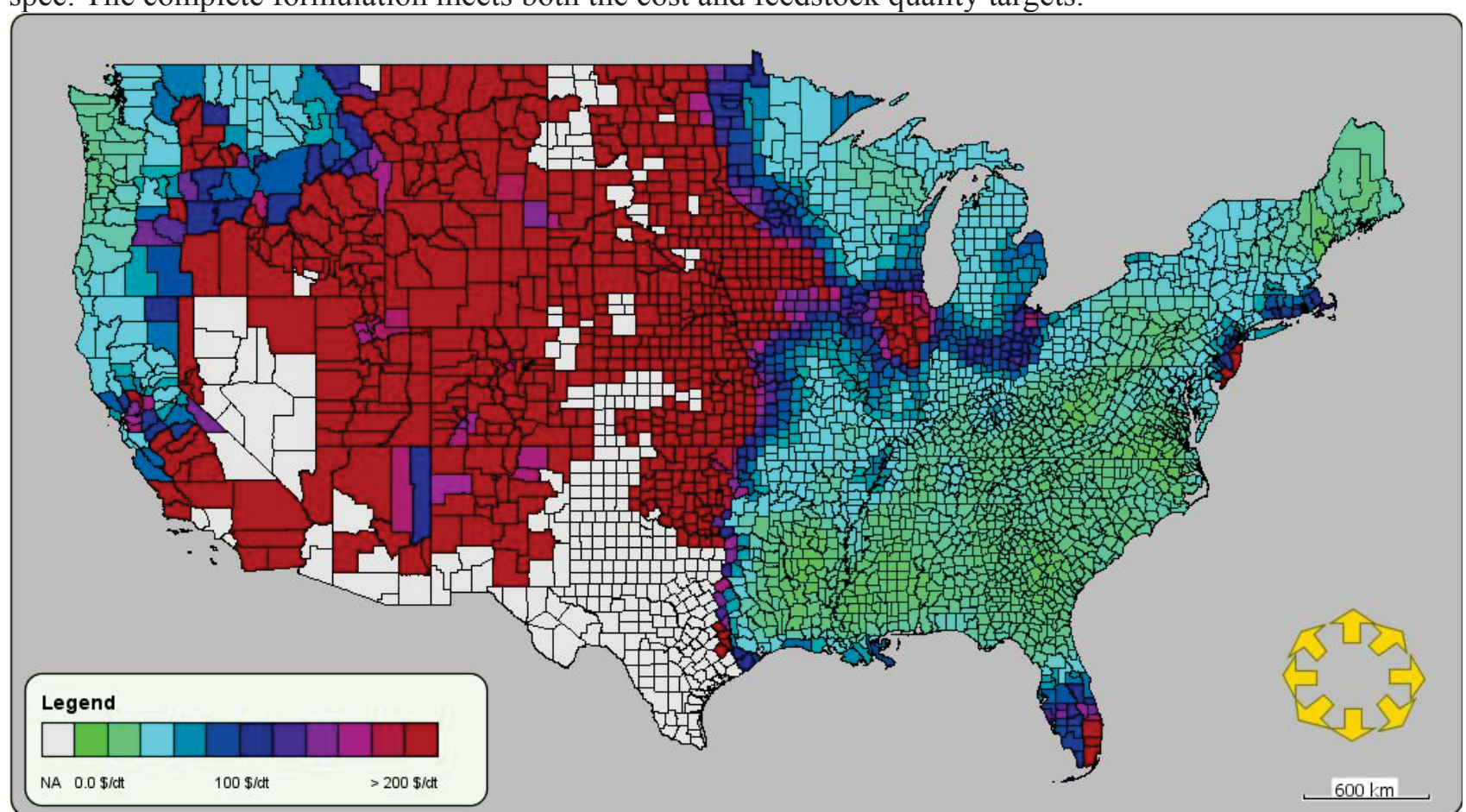

Figure 8. Farm gate/forest landing cost profile for forest thinning, logging residue, and loblolly pine blends in 2017. 
Table 1: List of costs and specifications for woody feedstocks and blends for thermochemical conversion.

\begin{tabular}{|l|c|c|c|c|}
\hline \multicolumn{1}{|c|}{ Feedstock } & $\begin{array}{c}\text { Reactor Throat Feedstock } \\
\text { Cost (\$/ton) }\end{array}$ & $\begin{array}{c}\text { Formulation } \\
\text { Fraction (\%) }\end{array}$ & $\begin{array}{c}\text { Reactor } \\
\text { Throat Ash } \\
(\%)\end{array}$ & $\begin{array}{c}\text { Reactor Throat } \\
\text { Moisture (\%) }\end{array}$ \\
\hline Forest Thinnings & 76.40 & 40 & 2.25 & 10.0 \\
\hline Logging Residues & 74.13 & 40 & 2.25 & 10.0 \\
\hline $\begin{array}{l}\text { 6"-8" Purpose Grown } \\
\text { Pine }\end{array}$ & 98.52 & 20 & 0.5 & 10.0 \\
\hline $\begin{array}{l}\text { Delivered } \\
\text { Formulation Totals }\end{array}$ & $\mathbf{7 9 . 9 2}$ & $\mathbf{1 0 0}$ & $\mathbf{1 . 9}$ & $\mathbf{1 0 . 0}$ \\
\hline
\end{tabular}

The supply system design for the Southeast blends the three chosen feedstocks (thinnings, residues, and pulpwood) inside the "depot" which is located inside the biorefinery gate (Figure 9). Initial harvest, collection, and preprocessing occur at the landing while secondary preprocessing, storage, and handling occur within the gates of the biorefinery. For the thinnings and pulpwood feedstocks, harvest and collection involve a feller buncher and a skidder (Figures 11 and 12). Residues do not include a harvest and collection operation (Figure 10). At the landing all feedstock are chipped but only pulpwood includes a debarking process. For each feedstock, chips are transported to the "depot" at the biorefinery in a semi and chip trailer. Within the depot at the biorefinery, storage, and handling and queuing include an asphalt pad, loader, conveyors, truck scale, and electro-magnet. For pulpwood preprocessing involves a grinder and a waste heat dryer. For thinnings and residues, preprocessing includes a chip cleaning operation as well as a waste heat dryer and grinder. 


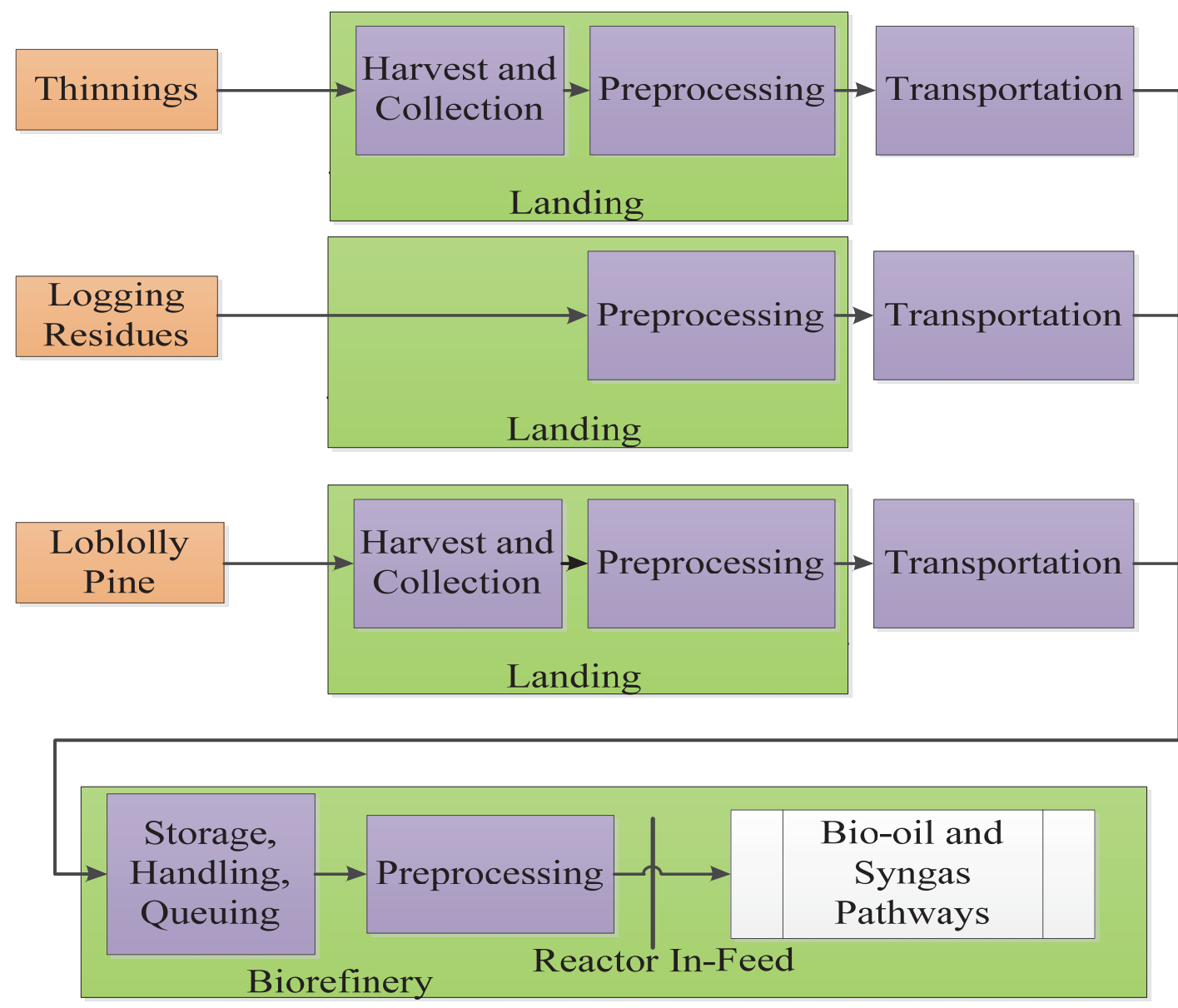

Figure 9. Supply chain design for formulated forest thinning, logging residues, and loblolly pine.

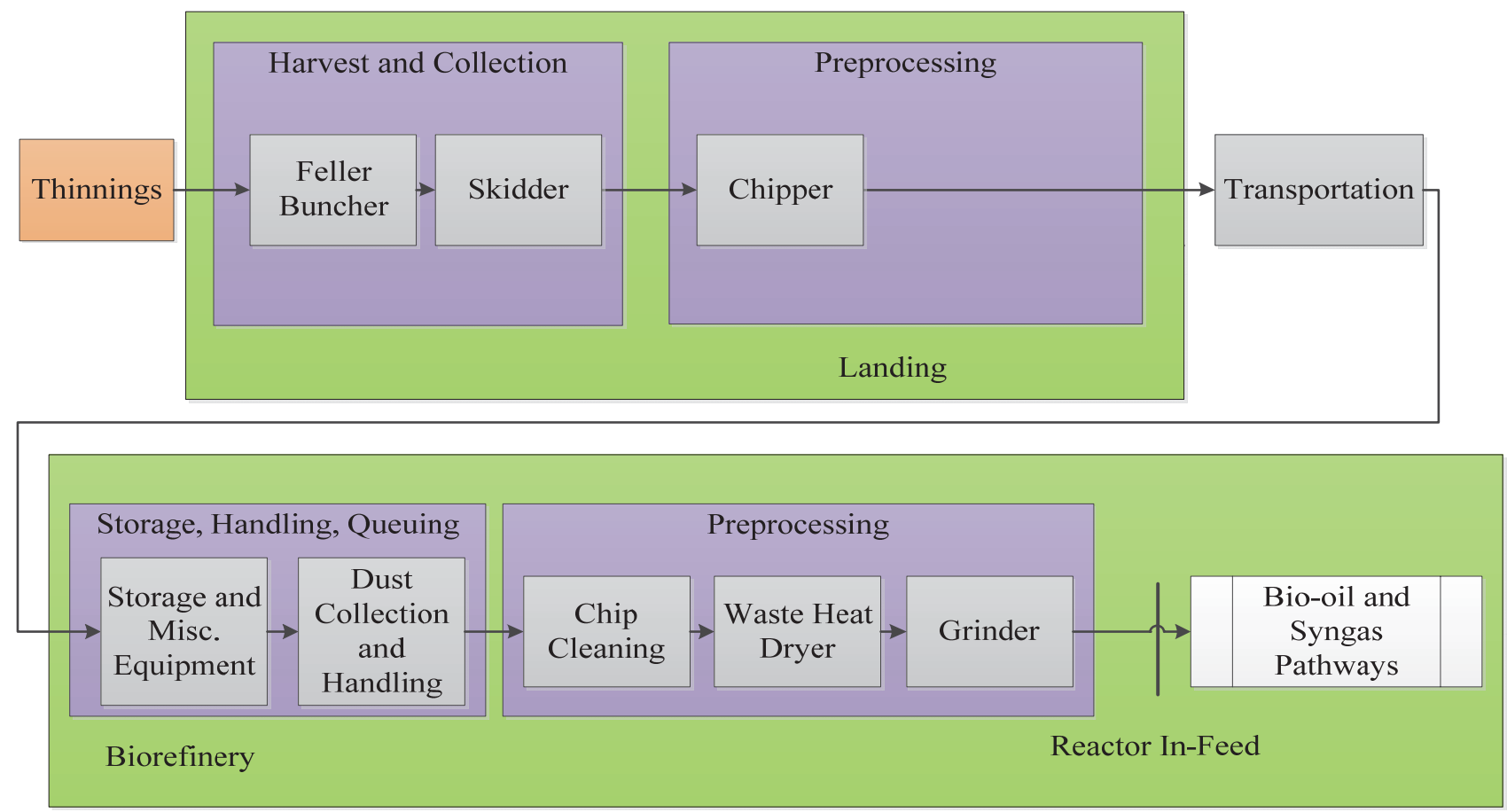

Figure 10. Detailed supply chain design for forest thinnings. 


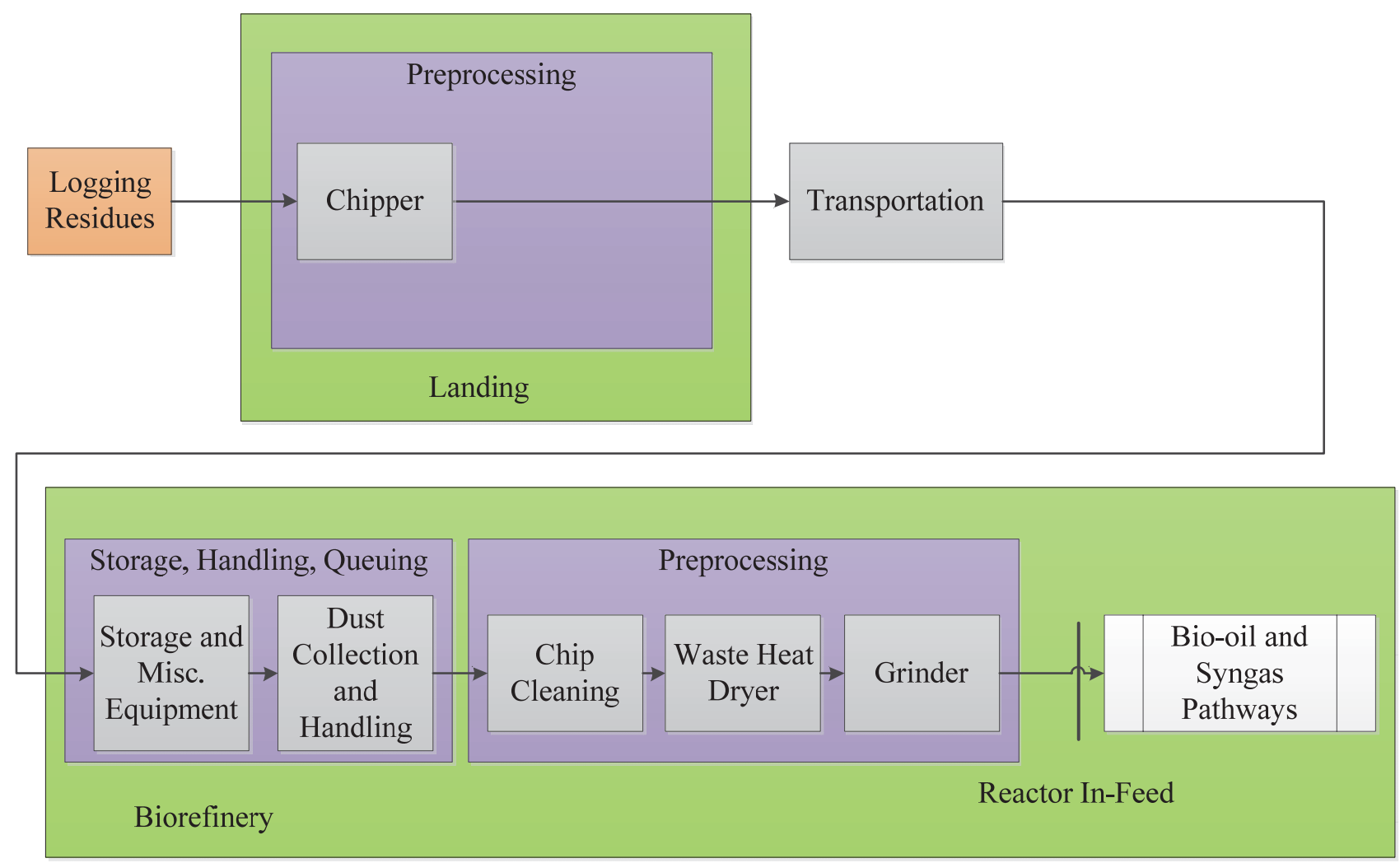

Figure 11. Detailed supply chain design for logging residues.
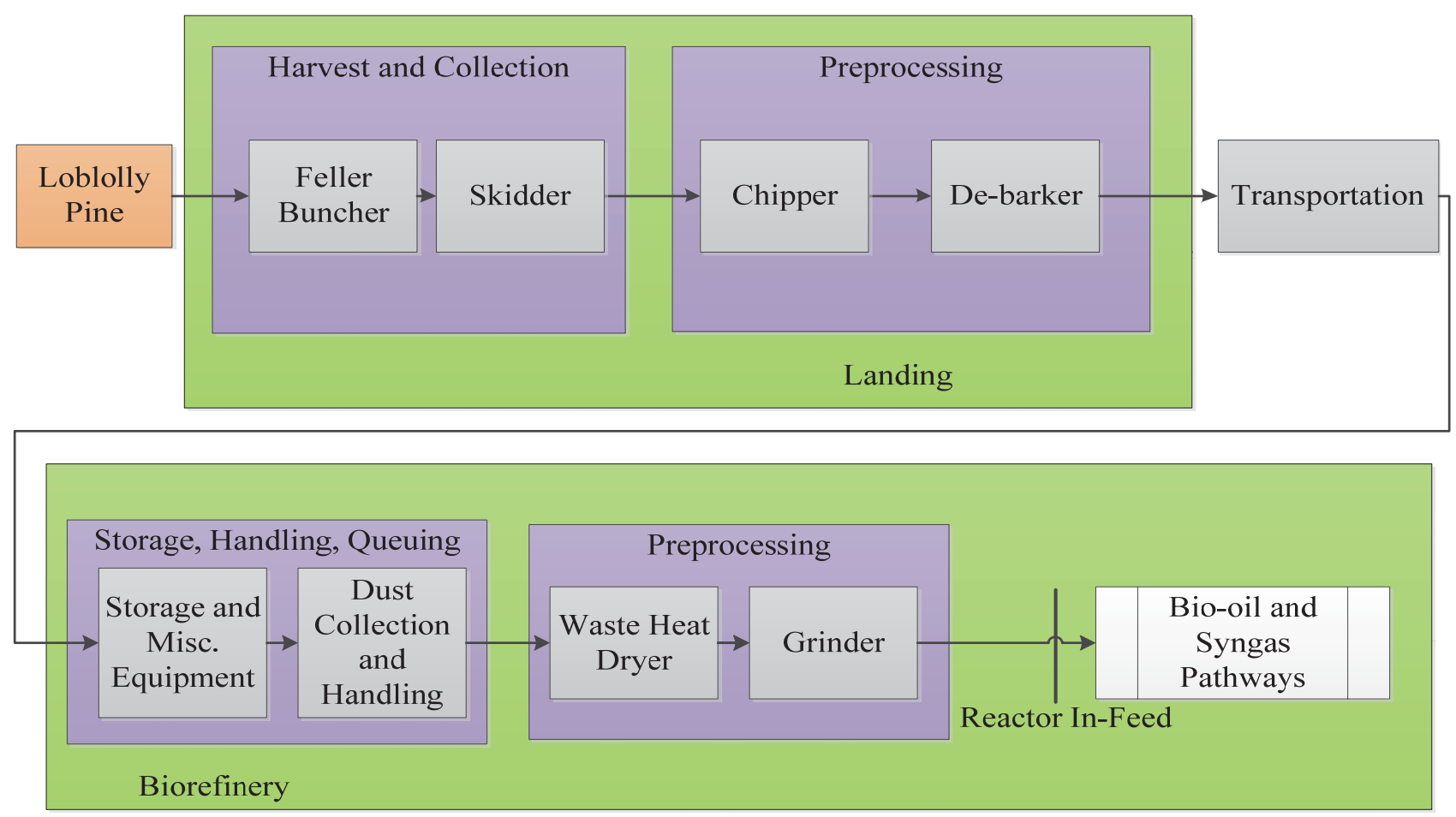

Figure 12. Detailed supply chain design for loblolly pine. 


\section{CONCLUSIONS}

Preliminary results on feedstock supply chains delivering material to cellulosic sugar, bio-oil, and syngas conversion pathways demonstrate that with the ability to blend multiple feedstocks and include some preprocessing operations it is possible to acquire much high volumes of material, reduce feedstock variability and meet the required $\$ 80 /$ ton cost of material to the throat of the biorefinery. Much more research needs to be done both on the performance of blended material as well as the blending strategies themselves. In addition, the current pre-conversion systems are expensive and those costs could prove to be a significant challenge when trying to meet the future cost targets. However, there is on-going research at the INL as well as universities and industry to address these challenges.

\section{REFERENCES}

\section{DISCLAIMER}

This information was prepared as an account of work sponsored by an agency of the U.S. Government. Neither the U.S. Government nor any agency thereof, nor any of their employees, makes any warranty, expressed or implied, or assumes any legal liability or responsibility for the accuracy, completeness, or usefulness, of any information, apparatus, product, or process disclosed, or represents that its use would not infringe privately owned rights. References herein to any specific commercial product, process, or service by trade name, trade mark, manufacturer, or otherwise, does not necessarily constitute or imply its endorsement, recommendation, or favoring by the U.S. Government or any agency thereof. The views and opinions of authors expressed herein do not necessarily state or reflect those of the U.S. Government or any agency thereof. 